\title{
And Still They Persisted: A Discussion of Indigenous Students Perspectives on a Year in Pre-Nursing Transitions
}

\author{
Kathy Snow \\ Cape Breton University, \\ Sydney, Canada
}

\begin{abstract}
Access and Transitions Programing has been a focus in Canadian Educational reform for over fifty years. Though made smaller through transitions and access supports, the gap between nonIndigenous and Indigenous students' attainment in higher education, remains large. One has to ask why? Evaluation of said programs in current literature is dominated with Eurocentric approaches and bias based in institutional needs such as retention, attrition and graduation rates. However, the statistics do not tell a complete story about how Indigenous students are navigating post-secondary experiences. Through the lens of the Medicine Wheel the experiences of four women participating in a Pre-Nursing Transitions Program (PNT) at a western Canadian University will be discussed. The results of this case study which was conducted during the 2013-14 academic year identify clashes between the Eurocentric paradigm of the University and students' values. At face value, conflicts centered around prioritisation of family, types of knowledge valued and the way information was presented. However, these conflicts speak to larger issues around the construction and intention of transitions programming and this article aims respond with a word of caution for post secondary institutions however well intentioned aiming to respond to the 2015 Truth and reconciliation call for indigenization of the academy.
\end{abstract}

Keywords: persistence; transitions; indigenous pedagogy; achievement gap; higher education reform.

\section{Introduction}

A growing number of Indigenous students are graduating high school and entering post-secondary education but the gap between Indigenous and nonIndigenous students' university completion continues to grow (Parkin, 2015). 
Increased enrollments at post-secondary have been supported by the implementation of Access and/or Transitions programs for Indigenous students' entry and preparation yet evaluations of their "effectiveness" remains elusive (Maltest \& Associates., 2004; Williams, 2004). In a review of literature, it was found that very little literature examined Access and Transitions programs ability to support students to graduation. The limited data that was found located the evidence in the language of institutional needs (retention and attrition) rather than student needs (persistence or life impact). It should be noted that much of this research was dated and evaluated the persistence decision making process of students using models such as Tinto's $(1975,2012)$ student integration framework. Tinto's framework, though considered one of foundational models for describing student persistence is problematic when describing Indigenous students, because it was not designed with them in mind, but rather the mainstream student population of the era, middle class youth entering university directly out of high school. One could further argue that both Access and Transitions programs are inherently colonizing practices through their naming with the underlying assumption being it is the students whose deficits must be accommodated (Access) or in the case of Transitions programs, the students who must to adapt to the university system and culture.

Indigenous scholars such as Marie Battiste (2013) have argued that colonization continues through education with the organization of learning and there is a need for Indigenous people to make their voices heard to begin to decolonize and re-frame thinking around education in Canada. This research set out to lend evidence to Battiste's call by examining a Pre-Nursing Transition program designed for First Nations students from First Nations perspectives. The study question developed in consultation with members of the Indigenous community at the university became: What organizational and institutional structures support student persistence? The response to the question that is shared in this research forms two narratives. The first story describes program structure and aspects of programming that support and hinder positive persistence decisions. While the second story paints a picture of the resilience of the women within the program. Women who did not succeed because of the university, but perhaps in spite of it. The lens or framework used to evaluate the response, was not that of Tinto, nor was it based in institutional measures of success. Instead, within this article I further discussion of higher education reform from the perspective of the medicine wheel a framework found almost universally in First Nations groups within Canada and used to describe wellness and balance for individuals. I begin the article by setting the stage and sharing a brief background on transition programs and then describe the context of the Pre-Nursing transitions program and the methodology of the study. I share the stories of three women who persisted in transitions and share the themes arising from their stories through the universities ability to support persistence through well being as described by the medicine wheel. Finally, I close with a discussion about what this work does to extend the conversations around the decolonization of higher education. 


\section{The Background}

Many post-secondary institutions in Canada, like the one that provided the setting for this research, offer separately named Access and Transitions programs. Access programs distinguish themselves from Transitions by focusing on mitigating barriers to access, such as applying modified entry requirements or physically locating classrooms in communities that need them. Transition programs focus on transitioning students into mainstream educational provisions by offering a period of preparation that has been tailored to meet students need. Philosophically the two types of programs are different but the actual application of supports offered by both types of programs overlaps to the extent that it may be difficult to distinguish them in practice. For the purpose of this article, the term transitions program will be used throughout because this is how the university chose to identify their program. However, the term may refer to either or both types of programming due to the limited literature available and the natural connections between the two.

From an institutional perspective, transitions programs appear to have made some difference in graduation rates for Indigenous students though little empirical evidence exists as to how or exactly how well they work (ACCC, 2010; Valentine, Hirscy, Bremer, Novillo, Castellano \& Banister, 2009). The structure of transitions programs vary but most commonly include revisions to the entrance requirements for the target student population alongside pre-university orientation workshops, the introduction of cultural content, preparatory credit courses, mentoring programs, tutoring, academic advisement, financial and personal counselling, housing and childcare assistance (Association of Canadian Community Colleges (ACCC), 2010; Anonson, Desjarlais, Nixon, Whitemand, \& Bird, 2008; Gregory, Pijl-Zieber, Barsky, \& Daniels, 2008; Hardes, 2006; Smith \& Gottheil, 2011; Swail, Redd, \& Perna, 2003; Valentine et. al, 2009). In the few qualitative studies examining student experiences that were found, a list of promising practices for transition program design has been identified: the importance of a multifaceted approach, academic preparation, family support, faculty support, and flexibility to allow students to maintain an active presence in home/community (Astin, 1984; Barnhardt, 1994; Guillory \& Wolverton, 2008; Larimore \& McClellan, 2005; Reyhner \& Dodd, 1995). In an examination of the study of nursing education specifically, successful Indigenous programming appears to include the aforementioned features with the addition of the early promotion of applied nursing skills (Kulig, Lamb, Solowoniuk, Weaselfat, Shade, Healey, White, \& Crowshoe-Hirsch, 2010). Critics of transitions programs have claimed universities design and offer these programs as a form of benevolent charity through an attempt to mitigate student deficits instead of examining the factors leading to persistence and how this might impact the larger university organization (McMullen \& Rohrback, 2003; Munro, 2012; Walberg, 2008). In an investigation of Australian transition programs, Fleet and Kitson (2009) criticized transition programs as being providers of short-term add-on "fixes" rather than actual support mechanisms to address the broader changes needed to combat the discrepancy between Indigenous and nonIndigenous students' persistence. Recent work by Fleet, Wechmann and Whiteworth (2012) outlined the need for holistic support networks which reiterated the need for collaboration between university, family and community 
to support students as one of the most significant factors enabling students to persist. However valuable these shifts have been in promoting persistence Walburg (2008) and Battiste (2013) claim the fundamental differences between the epistemologies of Western and Indigenous world views are not really addressed in post-secondary educational design. The Truth and Reconciliation Commission of Canada (2015) identified this conflict as ongoing colonization through Eurocentric approaches to teaching and learning and calls for the adoption of Indigenous pedagogies into mainstream educational offerings. This is no easy task. Indigenous students entering post-secondary may be from one of three distinct cultural groups: First Nations, Inuit or Metis, and within these groupings members of different cultural groups again. The heterogeneous nature of Indigenous student populations entering higher education further complicates social and academic integration from an organizational perspective because a universal Indigenous approach cannot adequately meet diverse students needs (Bastien, 2004; Martin \& Kipling, 2006; Timmons, 2009). To reduce "melting pot" effects, this research does not set out to describe Indigenous student experience universally, but rather the experience of one specific group, urban raised First Nations students in a pre-nursing program at a large urban centre.

What is my role in sharing this story? As a non-indigenous researcher, my knowledge of First Nations experience will always be limited. This research is the result of two years of work with the community in question, a year of consultation and direction seeking and a year of conversations with students and faculty. Ideally these stories would be written by the women themselves, but they were busy, getting on and getting through university to obtain their goals. My intention was to act as an ally; to give voice to those not in a position to speak or write but who wanted to effect positive change for future students by sharing their experiences. So I offered my time and a safety net, an outsider with nothing to gain or lose, who could voice authentic experiences with no risk to those who spoke. The choice of the medicine wheel as analytic frame, and the degree to which this was successfully done also speaks to my own process of unlearning (Wilson, 2008) and decolonizing myself.

\section{Setting: The Pre Nursing Transitions (PNT) Program}

The development of the case study was informed and guided by the Director of Indigenous Programming at a western Canadian University (referred to as the University throughout the remainder of this article). The Director stated, like many transitions programs across Canada the cost/benefit equation of the Indigenous Pre-Nursing Transition (PNT) program within the University's budget was being questioned. The program was expensive to operate and graduation rates were low (personal communication, 2011). Facing institutional funding cuts the Director wanted to know what aspects within the current PNT program supported students' transition beyond the numbers that could be obtained from the registrar's office. Of Indigenous descent, the Director also had first hand experience with transitioning to university and wanted to know: What aspects of the program worked well for the students and what areas needed improvement? Also, what evidence could be offered that illustrated the 
programs were having a positive effect on students to support its continued existence?

The PNT program of the University was relatively resource heavy in comparison to the first year nursing offerings for mainstream students. PNT like the mainstream pre-nursing program was designed to completed in one year and included all of the first year pre-requisite courses for the three-year Bachelor of Nursing. The difference between the Transitions program and the mainstream pre-nursing year was that Transition candidates were "cohorted" and participated in specific sections of the core biology courses which were all taught by the same instructor. Cohorting reduced the typical class size of the university from over 100 to approximately 20 students. In addition, PNT students were expected to participate in mandatory tutorials, visit an academic/personal counsellor monthly as well as take part in a week long orientation program. No specific Indigenous practices were adopted in course or program design and Indigenous content was limited to elective courses in Indigenous studies. The instructor of the core courses did not alter the content or structure of the lessons from the mainstream sections but provided PNT students with additional learning supports such as recorded lectures and pre-instruction Power Point notes, which were not provides to the parallel mainstream classes. Rather than being program specific, cultural support was provided for all Indigenous students at the University through an Indigenous students' centre. The building was home to a full time Elder in residence and offered a friendly space to spend time, computer access, free printing and a lunch room. Staff working in the centre coordinated a variety of social and cultural events open to all students as well as facilitated mentorship opportunities.

\section{Methodology and Methods of Data Collection}

Approximately a year was spent in consultation with the Director of Indigenous programming, the faculty instructor described above, the administrator of the PNT, the academic councillor of PNT and several program leads of the varied Indigenous focused programs offered at the University before a methodology was determined. Through these pre-research conversations, it became apparent that the University needed more qualitative evidence about the function of the PNT. All of the aforementioned community members discussed the need to look beyond the statistics to see the real value of the program for the students, with the most poignant example coming from the Director as she outlined the "problem" of persistent students, or more accurately, the funding problem created when students did not complete the ten-month program in the allocated ten months. As a non-Indigenous researcher focusing on questions involving Indigenous participants I felt the methodology needed to be positioned in a manner similar to the aims of the program, as a "middle ground" or bridge between two worlds (Augustine, 1998). The research methodology chosen was case study, to reflect the unique population of students in the particular context. I attempted to blend both Indigenous and non-Indigenous epistemologies through the use of predominantly qualitative methods with open ended interview protocols that became sharing sessions rather than interviews, as a form of bricolage (Kovach, 2009; Lowan-Trudeau, 2012). The research approach was also grounded in relationship building guided by the seminal 
work of Kirkness and Barnhardt (1991) 4Rs: respect, relevance, reciprocity and responsibility. Data collection took place through a series of four individual meetings with each self-selected student candidate during one academic year, September, 2013, to May, 2014. Through chain sampling, from participating students' identification of key influences on their persistence additional interviews were conducted with the academic counsellor and the primary faculty instructor. The sessions were recorded, transcribed and analyzed for themes using in vivo coding according to the protocols established in Saldana (2013). Trustworthiness of the data was achieved through a process of member checking and research collaboration with the participants. My interpretations were brought back to each participant prior to commencing the subsequent interview and interpretations were verified or corrected until the participants identified their experience had been accurately captured and represented. Both the primary instructor of the biology courses as well as the academic counsellor were also interviewed at the end of the data collection period in an effort to refine themes as they emerged from the data and to triangulate. The participants themselves, became co-researchers rather than the subject of research. As the year progressed they brought me stories and analysis of their university experience. They searched to describe concrete factors that could contribute to improved learning for the students following in their footsteps in subsequent years. Through these stories a picture of who they were, their motivations and resourcefulness became apparent.

\section{The Women}

Three self identified First Nations students participated in research conversations but asked to remain anonymous, therefore pseudonyms have been used. All women gave their time freely without incentives. When our official communications concluded at the end of the transition year four themes emerged (1) organization of learning, (2) scaling the university experience, (3) pacing the program and (4) faculty's role in advocating for students. Each of these themes begins to emerge from the students' stories that follow.

\section{Carol}

Carol entered the pre-nursing transition program as an adult learner after a long gap in education as well as through a non-traditional high school graduation route. On our first meeting Carol outlined how challenges with her step-father led her to marry early as an escape from home. After raising her family and working her way up to a successful career in sales through a variety of entry level jobs. Carol was highly motivated to return to school, not only because of her own educational goals but to be able to move into a career that offered more stability to her family. Carol regularly cited her children as motivation factors for her return as well as ongoing persistence efforts over the course of the year, both in terms of strategizing her own success, "my kids, they depend on me, and I don't have the option to not do what I need to do" as well as the change her new lifestyle brought to the home, "I'm home, I mean I am very busy, school is busy but I am home [more] with the kids, I notice they are a lot happier.". Carol was responsible for the primary care of her children as well as felt responsible for care of her extended family. When an extended family 
member, who lived in another province, fell ill during the term Carol reported feeling immense guilt that she could not be physically there to support her. She felt the stress of this situation would have caused her to leave the University entirely had it not been for her close relationship with the transition program mandated counsellor. Carol often identified her relationship with the counsellor as an important aspect of her stress management, "I don't have time to let it [stress] creep in and if it does I just go knock on the counsellor's door with a box of Kleenex". Carol also identified the primary instructor of her core biology classes as important to her success because the instructor appeared genuinely interested in students, but Carol was also critical about the way in which the content of the courses was presented,

she is a fantastic instructor and she cares and all those things, but I think she is like so smart that like her language is very intense and it was well over and above what we were ready for and that was a huge difficult struggle throughout. ..I have spoken to her about it before, there is a disconnect between what I am being taught and I think I understand ... And there has been [from the beginning] and that has been a very frustrating point for me.

Carol suggested both the type of content selected for the program (general science as opposed to nursing specific) as well as the way it was structured (from cells to systems instead people to parts) increased the challenge of the program,

We are still learning the individual pieces the intestine, all of that, and apparently now we are going to learn how it works, apparently by the end of next term that's going to be the big reveal. We'll see.

She was also disappointed in what appeared to be a complacency on the side of the institution with regard to expectations saying "[The instructor said] the average is $60 \%$, and that's a good score... when I was in high school that was not good...I'm just flabbergasted." Throughout the year, Carol returned to these feelings of disconnect, that the university had somehow gotten the process of learning backwards. In spite of these feelings, Carol completed the PNT, in the year she entered and was accepted into the competitive nursing program. However, it is important to note that Carol deliberately took courses in advance of entering PNT, to "test out" university prior to entering PNT. When asked at the end of the year what motivated her to complete her answer was very simple, "how many times have I been told no because I don't have that piece of paper... so I guess just to prove to everyone else I guess, I will feel good about it.". She felt very alone in this goal, and as a single mother she had the added pressure of supporting her children now and in the future. "Getting the paper" represented proof for her children and herself that things could be different.

\section{Anne}

Anne also left home at an early age and returned to complete high school as an adult learner. Anne identified herself as a high achiever stating that, "In high school up until the end of my grade 10, [the year she left school] my marks 
ranged from 85 to 95\%." Anne had successfully graduated from a college program in a different health care field and left that career to enter the PNT. She was married without children and indicated her spouse was extremely supportive of her decision to return to school, "having my husband, he's wicked, he is amazing it's so nice to have someone that is your cheerleader and is just so supportive... during exams he cooked dinner every night and he did laundry and like all these things.". Together they had prepared a financial plan in order to be able to pay for the nursing degree without, she hoped, having to access student loans or bursaries. Anne, although considered a first year student had started taking courses at the University one term prior to her start in the PNT program in an effort to better prepare for her return to school. She did not feel she needed the counsellor and participated only to the extent that she completed the mandatory minimum number of meetings required of the PNT program. Anne was highly self-motivated and didn't feel she had time for socializing at the university. After the first term of varied attempts to connect with both members of her class, the Indigenous community on campus and the nursing faculty she withdrew from social contacts with the university generally. The only relationship Anne attempted to maintain was that with her primary instructor,

she's also younger...so she's a lot more personable, so [she is] more inclined to have a personal conversation where a lot of other instructors really aren't a lot of times they seem very busy they are approachable in that you can ask them questions in regards to assignments and stuff but other than that they tend, they are gone...

Anne identified this action as strategic. It was not that she did not want to have connections on campus, but as an adult learner she approached school like a job, arriving on campus daily in a 9-5 pattern. Rather than spending her out of class time in social activities she preferred to seek out quiet corners on campus to study. Originally, this home was the Indigenous student centre because she found it to be a comfortable place and welcoming space. By the mid point of the year, as her familiarity with the campus grew she moved on to find study areas in the nursing building, because she wanted to overhear and learn about what she needed to know after PNT. In her explorations with relationships on campus, once she determined a particular relationship to be a "time waster" because it did not directly lead to gains academically or contribute to her professional goals she ended it. The only non-academic activity Anne added to her daily campus routine was a regular workout time at the gym, which she said was important to managing her stress levels. Anne was highly motivated, before the completion of PNT she had mapped out an accelerated program for herself for nursing so that she could enter into a master's degree. Her goal was to enter nursing on her academic standing alone by not using one of the seats reserved for Indigenous students. She achieved this. When I asked her what advice she had for anyone considering entering PNT she said, "you can succeed if you use the supports, if you are committed, you really have to commit to being here in general, so if you are at that point, you know for sure that is what you want to do, and you don't let anyone distract you from that.". For Anne, 
completion was all about mitigating distractions and obstacles with a sense of humour. In our interviews we laughed a great deal about the challenges she faced and her recounting of her response to them.

\section{Mary}

Mary entered the PNT in a more traditional route, with a three-year gap between graduation from high school and application to the University. Not confident in her ability to be successful at the university level upon graduation from high school Mary completed a two-year college program first, "I wasn't ready to commit to university, a long program and a lot of money right out of high school... I knew I was interested in something in the medical field but I wasn't sure what that was.". However, during her internship in this program she decided she wanted a more challenging career in the medical field. She lived at home with her mother and siblings just outside the city and had a long daily commute using public transportation. Money was an important issue for Mary as she not only paid for her own tuition, but also contributed to the family income by paying rent and helping out financially as needed. Mary maintained her job on a part-time basis upon entering the University full-time through traditional channels. Shed joined the PNT program six months after her original start due to a chance encounter with another Indigenous student at the Indigenous student centre. Mary like Carol and Anne identified her immediate family as a family of "workers" who did not fully understand the complexities she faced with her return to school, "I don't have a horrible life, but I want better things, for my family, even though they don't really acknowledge [my efforts]." Mary maintained social contacts with both friend she made within the PNT and also from her previous term on campus. She regularly met "the girls" for coffee and "gossip", although she intentionally limited these contacts to the school day and deliberately chose not to socialize on the weekends reserving this time for her friends and family outside of the University. Prior to entering PNT, Mary had a challenging first term on campus and viewed it as a learning experience because she felt it was not the content of the courses that was difficult, but rather, the course load balance and time management that had caused her the most problems. She attributed this at least in part to her lack of familial mentorship,

it's really hard for me, no one in my family went to university so I can't say oh my mom is pushing me or whatever, um I would say it's just myself, I just changed a few things, obviously, studying habits, you know I learned, like how to group what with what and just go from there, self motivate myself.

Mary also outlined stress in relation to the size of the university. Having come from a smaller school outside the city she found both the physical size of the campus and the number of students in the typical classroom to be daunting. She identified the scaled down PNT cohort as an important feature in establishing her connection to the University. Although she did not develop relationships beyond the level of "familiar faces" in the cohort, Mary appreciated the fact that she was both noticed as a person by classmates and the instructor because of the small class size. At the end of the PNT year Mary chose not to apply to nursing 
but instead to return for a second year in PNT. Her plan was to enroll in the nursing electives open to any university student as well as re-take some of her previous courses where her grades had not been strong. Having learned from her early experiences in the university, that choosing a good balance of courses was critical to success, she wanted to lighten her load in the nursing program by reducing the course credits she would need initially as well as ensuring she had the foundations in physiology and anatomy provided by the PNT.

\section{The Medicine Wheel as Analytical Lens}

Pamela Toulouse (2007), an Ojibwe scholar, has put forward the argument that Indigenous Peoples' academic success is inherently tied to self-esteem and identity, which she describes using the medicine wheel. This lent further evidence for the need to an alternative evaluative frame. The Medicine Wheel is one of the most widespread symbols found among North American Indigenous cultures (Canada Royal Commission on Aboriginal Peoples, 1996). Each of the four directions (East, North, West and South) of the wheel may be attributed different meanings based on the cultural heritage of the speaker, but each reflects holistic attributes of an individual's life that should be kept in balance with the attributes of the other directions (Landon, 2012). These attributes include emotional, physical, mental and spiritual domains and should one aspect of a person's life fall out of balance all others are impacted (Toulouse, 2007). Entering university represents a major change in an individual's life causing many aspects to shift in and out of balance as a student adjusts to the new environment. Because of this, it was through the lens of the medicine wheel that I chose to describe the students' experiences rather than the more traditional student integration framework of Tinto (2012) which as previously mentioned is not relevant for Indigenous students and focuses on retention from an institutional perspective. As a non-indigenous researcher working with First Nations participants, I was challenged with unsettling myself, second guessing my own understanding of experiences and post-secondary education. Using the medicine wheel became a tool for me to evaluate my own expectations and question factors impacting student persistence not formally represented in literature.

\section{Learning from the stories}

In reviewing the transitions program through the lens of the medicine wheel, I added two more voices, that of the instructor of the cohort courses and the oft mentioned academic counsellor. Here we see a second and perhaps more important story emerge. One that attests to the resilience of the women in the face of change and the challenges they must negotiate to persist: (1) central role of family, (2) strategies to navigate two worlds (3) isolation and the (4) desire to give, serve and succeed for others. It is important to note, these are the characteristics the students brought to the program and the areas that were not served well by the university.

\section{The East: Emotional Domain}

The East or emotional domain describes your mental state and how your emotions impact your relationships with others (Toulouse, 2011). Student 
participants universally approached their academic journey as one that needed to be completed alone. Their comments evidenced both feeling isolated from family as well as a need to "make in on my own". When directly asked about the changing nature of relationships, all three students identified varying degrees of support with regard to familial understanding of the academic journey. All three women indicated because they came from a family of "workers" they were often misunderstood. Hardes' (2006) identified that for many Indigenous students joining the university community means, at least to some degree, a separation from family community. The academic counsellor reiterated examples from students and identified familial relationships as a key theme impacting persistence,

you know when you have students that have family who don't understand what it takes to be a student at university or they are coming in from you know the north on a weekend and say no we want all your attention meanwhile the student is caught between working on their studies or being there with their family ... they are caught in that catch 22. I've heard that story so many times.

Pidgeon (2009) proposed that Indigenous students must negotiate a challenging balance between the cultural values of home versus the western values given priority at the institution, with both worlds conflicting in various realms of decision making and prioritizing. The student participants discussed this conflict indirectly. All participants were hesitant to join the PNT community, citing family commitments and life outside the university as more important than investment in new relationships that were seen as transient. There was also reluctance related to involving family members in the University environment, with the only exception being the Indigenous students Christmas party. Gold (2011), has shared similar evidence claiming that family connections take priority over educational group membership for Indigenous students. Sitting between these two worlds lead to feelings of isolation and the search for someone to identify with. For Carol the search for advice and balance came from regular meetings with the academic counsellor. Anne on the other hand, felt the academic counsellor was at times a burden or requirement of the program and sought out a mentor through the Indigenous mentorship program at the University. Anne however ended the mentorship relationship after only a few brief meetings with her mentor because she did not find him relatable. Anne switched to a complete separation of relationships of university and home and found her support from her husband. During the course of the year, Mary never quite found a grounding relationship on campus. She had many loose social connections with classmates and other Indigenous students on campus, but she did not socialize with these students outside of the university environment, nor did she introduce them to her family. The isolation and lack of role models is a theme that has been addressed frequently in the literature, but has yet to be addressed in practice effectively (Battiste, 2002; Hare, 2011; Kanu, 2011). Students initially reached out for emotional connections in the university, but finding few or not prepared to invest the time needed to build deeper connections they adopted coping skills that helped them persist alone. 


\section{The South: Physical Domain}

The south or physical domain of the medicine wheel represents basic needs; food, shelter, health and general well-being of an individual (Toulouse, 2011). For Carol the motivation for returning to school was based in her ability to better meet the physical needs of her children,

The job that I had, I mean it paid a lot of money, it was very good financially but, um it's also a lot of hours and a lot of time, so it was like 6 days a week, always evenings and weekends, and like I never saw the kids, the kids were shipped around from daycare, to babysitters...They still need me right, I found my son really struggled a lot with um, me being gone all the time.

Childcare and family caregiving have been found to be critical challenges impacting Indigenous women's education post-secondary school completion because of the absence of supports such as adequate/affordable childcare (ACCC, 2010; Kitchen, et al., 2010). The evidence presented by the students in this work indicated this remains an ongoing problem, in particular for women. Carol indicated the delay in her return to university was directly attributed to her children, "we started a family and so my education got pushed back.". While Anne, who did not have children, indicated her delayed entry at university was caused by her need to meet her own physical needs after being forced to leave home at an early age. She only felt confident now to return to school because she and her husband had planned and set aside savings to allow them to maintain their lifestyle with the loss of her salary. Anne had faced difficult times in the past, going from a straight A student to a drop out in high school because of the large number of school days missed for work once she was living on her own. Both Mary and Carol were still facing this challenge, working and caring for family while trying to study. The same commitments that motivated them to return to university, the ability to provide better support for their family, were also the ones that caused them to miss time. Flexible and blended learning designs have been cited in the literature as possible means to further support students who must miss time (Donnelly, 2010; Means, Toyama, Murphy, Bakia, \& Jones, 2009; Woltering, Herrier, Spitzer, \& Spreckelson, 2009). For all three student participants the online learning supports in the form of the Power Point course notes provided scaffolding for filtering and prioritizing face-to-face content, however they did not access recorded lectures also made available. When questioned, the women indicated that they found recordings too time consuming to listen to when they were already trying to catch up. Using the Power Point notes or gathering notes from other students helped to filter what needed to be learned into manageable pieces more efficiently. All women also indicated the instructor's flexibility, caring and advocacy were important to passing the course. Citing examples of permission to hand in late submissions, allowing extended absence for personal reasons and academic support for these absences, students contrasted the qualities of their instructor against other experiences of the opposite. At some points when listening to the women, I felt the university was holding them hostage because of their physical needs, because improving ability to meet physical needs was the primary motivator for 
all women, but structures in place for academic achievement made balancing current needs challenging. This is why the women relied so heavily and appreciated so deeply the flexibility of the instructor, because she humanized institutional processes.

\section{The West: Mental Domain}

In the mental sphere, defined as the cerebral activities of a person, students cited conflicts with the order in which materials were presented. The first conflict students identified related to processing of information. Both Carol and Anne indicated the presentation of the course content was exactly the opposite of their own understanding of learning. Their preference was for information to be presented holistically and then deconstructed as opposed to the presentation of smaller pieces building up to the whole, as exemplified by Anne in speaking about a theoretical physiology lesson: "I don't even know how to ask the question to better understand whatever it is you are talking about because I don't even know what you are talking about.". Within the Canadian context there is evidence that suggests that the conflict between Indigenous ways of knowing and the Eurocentric deductive approach to knowledge acquisition has indeed contributed in part to lower graduation rates for Indigenous students (Landon, 2012; OECD, 2017; Whitely, 2014; Zinga \& Gordon, 2014).

In their discussions of Indigenous pedagogy, Kanu (2011) and Slee (2010) raised the same concerns about the disconnection between holistic learning approaches and the Eurocentric deductive approach to knowledge acquisition. Each participating student acknowledged a level of disconnect from her desired profession, nursing. They felt there should be greater ties to the nursing community, nurses and a more obvious relationship between the content of their courses (biology and nursing) and their future role in the community as practicing nurses. Carol stated this feeling most blatantly,

I don't want to kill somebody, I want to walk out of here and feel confident that I know what I am frigging doing when I work in a hospital I don't want to go be unsure and what I am hearing from other nursing students is no, it's up to you to know, cause you know [coursework] and then you are not ready [for work in hospital].

The personal relevance of the course content and the "important" knowledge to retain for future was a large concern for students who felt this was not being filtered appropriately. Anne made a point of spending time in the nurses' student lounge, not to make friends, but to find information that would help her pass critical nursing exams. The desire for personal relevance for these women was not met. However, personal relevance has long been advocated by Indigenous scholars who note that this issue is at odds with the Eurocentric approach to standardized learning progression (Battiste, 2002; Munroe, Borden, Orr, \& Meader, 2014).

\section{The North: Spiritual Domain}

The north or spiritual domain refers to all the thoughts, activities and rituals that connect a person to the world (Toulouse, 2011). Contrary to evidence from the literature (Barnhardt \& Kawagley, 2005; CESC, 2003; Fleet \& Kitson, 2009), 
student participants in this research did not explicitly identify or recognize a spiritual disconnect between Western education systems and Indigenous ways of knowing. So it is here, we see an imbalance in the wheel. This absence in the study data does not necessarily indicate that one did not exist, but rather that the students were unable or unwilling to identify it. It is important to note, that all women were raised in and around urban centres and attended provincial schools prior to university entry. When these observations were discussed with the instructor, she responded,

High school is already so disconnected for many of the students...I've taught in isolated communities and there it is different, then you had [students who were] very culturally in touch and immersed and that is more the day to day life...in this cohort there is a mix of everything [backgrounds] but the bulk of the students are not in touch with their cultural roots.

The instructor's conclusion was evidenced in student comments as well. After using a word in the Ojibwe language, Anne stated: "I am trying to learn all these new words," indicating her disconnect to her heritage language. Students appeared to be distanced from traditional Indigenous languages and cultural activities. Anne made some attempts early in the PNT program to participate in Pow wows and other cultural activities however she became frustrated and began to see the events as "time wasters" in her overburdened schedule. Spiritual and cultural practice was not integrated into the students schedule either by the University or the students themselves, despite the fact that research in promising practices indicates that cultural competence leads to greater academic achievement (Chain, et. al, 2017). Although they identified some disconnects that they felt stemmed from the bias of the Eurocentric presentation of course content, they did not explicitly identify this as a cultural disconnect. When students were asked about the importance of an Elder in residence, only one student identified a desire to communicate with the Elder. All other participating students indicated this practice was foreign to them or something they had given up in their past. Battiste (2013) has claimed that the erosion of Indigenous culture, language and knowledge is an end result of the colonial education systems the students participate in and that students need to be reeducated in their own culture. To that end, the University provided open cultural events for all Indigenous students which the students appreciated. However, as the term progressed they spent less time involved in these cultural events as the demands for their studies grew.

\section{Conclusion}

The evidence presented in this paper is cyclical. As my relationship with the students deepened I learned and relearned what grounded persistence decisions and the personal costs students experienced because of their decisions. Initially, I saw the surface, the program critiques and supports as outlined as organization of learning, scale of the university, pacing and faculty advocacy. As the year progressed, I learned more about the complexity of university transition and the personal conflicts participants faced in relation to family, university 
membership, isolation and desire to help others. Entering university can be a highly conflicting space for Indigenous students, impacting their sense of selfworth, their relationships and identity. Negotiating this change is the key to persistence, but the mechanisms offered by post-secondary institutions need to at minimum acknowledge this complexity. The missing connection to the spiritual domain is not insignificant. Evaluated through traditional western lenses of student integration, spirituality is seen as unimportant, but Indigenous scholars tell us it is critical to identity and well being. The lack of formal recognition of spiritual (not religious) ceremony and practice and its role on persistence demands further study, but it is an area of change that higher education is cautious to enter. Ultimately, all students were persistent, although not necessarily successful in negotiating the transition program through the plan laid out by the University. Returning to upgrade or complete missing credits meant that students were taking up seats that could not be counted as "new intake" or "graduates" and therefore un-countable, which was the original problem identified by the program director in pre-research consultation. However, in response to University or budgetary critiques of lack of success from transitions these women have evidenced not only persistence from a positive perspective but also shared insights that would facilitate a greater Indigenous student centered focus for transitions programming. Moving forward, the implications for transitions design are:

1. Students' lives are complex, and western approaches to timelines and lock-step processes alienates students who may miss time because of family or other obligations. Flexibility of process and understanding are critical.

2. In connecting to the university space, relationships with instructors are critical. Faculty need to be aware of the central role they play in persistence decisions because they are the key face of the university for students.

3. Building on both of the above, a holistic approach to education is needed, not only in content, which has been oft mentioned in the literature but in supporting the connection building between school, family lives and individual well being.

These concepts are not new in public education. In essence the themes arising from this work speak to humanizing the educational experience. Postsecondary institutions have been far slower to adapt to the changes in educational approaches seen currently in public school. Transition programs aim to teach students how to adapt to the industrialized process of education seen at this level. But it is exactly this industrialized approach, large scale classrooms, standardized instruction and the positioning of student-faculty relationships that was identified as alienating to the students involved in this research. Until we begin to foundationally re-think and redefine the way we engage with students at the post secondary level we are guilty of perpetuating colonization effects regardless of how well intentioned our work is. Responding to the Truth and Reconciliations' call requires more than investing in improvements of sustaining programs built from colonial perspectives. Un settling and institution requires listening and taking time to understand the 
complexity associated with attending higher education and responding holistically using alternative frameworks such as the medicine wheel as a guide to evaluate and respond to the needs of the students.

\section{References}

Astin, A. W. (1984). Student involvement: A developmental theory for higher education, Journal of College Student Personnel, 25, 297-308.

Anonson, J. M., Desjarlais, J., Nixon, J., Whiteman, L., \& Bird, A. (2008). Strategies to support recruitment and retention of First Nations youth in baccalaureate nursing programs in Saskatchewan, Canada. Journal of Transcultural Nursing, 19(3), 274-283. https://doi.org/10.1177/1043659608317095

Association of Canadian Community Colleges. (2010). Colleges serving Aboriginal learners and communities: 2010 environmental scan. Ottawa, ON: Association of Canadian Community Colleges.

Barnhardt, R., \& Kawagley, A. O. (2005). Indigenous knowledge systems and Alaska Native ways of knowing. Anthropology and Education Quarterly, 36 (1), 8-23. https://doi.org/10.1525/aeq.2005.36.1.008

Barnhardt, C. (1994). Life on the other side: Native student survival in a university world. Peabody Journal of Education, 69, 115-139. https://doi.org/10.1080/01619569409538768

Battiste, M. (2002). Indigenous knowledge and pedagogy in First Nation's education: A literature review with recommendations. Prepared for the Minister's National Working Group on Education. Canada: Apamuwek Institute.

Battiste, B. (2013). Decolonizing education: Nourishing the learning spirit. Saskatoon, SK: Purich Publishing Ltd.

Canadian Royal Commission on Aboriginal Peoples (1996). Report of the royal commission on Aboriginal people. Ottawa, ON: Canada.

Chain, J., Shaperio, V., LeBuffe, P., Mackay-Bryson, A. \& American Indian and Alaskan Native Advisory Committee (2017). Academic Achievement of American Indian and Alaska Native students: Does social-emotional competence reduce the impact of poverty. American Indian and Alaska Native Mental Health Research 24: 1, pp 1-29. https://doi.org/10.5820/aian.2401.2017.1

Donnelly, R. (2010). Harmonizing technology with interaction in blended problembased learning. Computers \& Education, 33(3), 381-413. https://doi.org/10.1016/j.compedu.2009.08.012

Fleet, A., \& Kitson, R., (2009). Rethinking assessment in an Indigenous specific program. The Alberta Journal of Educational Research, 55(3), 397-413.

Fleet, A., Wechmann, K., \& Whiteworth, R. (2012). Professional pathways of Aboriginal childhood teachers: Intersections of Indigeneity and complexity. Australian Journal of Teacher Education, 37(9), 128-143. https:/ / doi.org/10.14221/aite.2012v37n9.7

Gold, S. (2011). Aboriginal student experience at the University of Alberta. (Unpublished masters' thesis). University of Alberta, Edmonton.

Guillory, M., \& Wolverton, M. (2008). It's about family: Native American student persistence in higher education. The Journal of Higher Education, 79(1), 58-87. https://doi.org/10.1353/jhe.2008.0001

Gregory, D., Pijl-Zieber, E. M., Barsky, J., \& Daniels, M. (2008). Aboriginal nursing education in Canada: An update. The Canadian Nurse, 104(4), 24-28.

Hardes, J. (2006). Retention of Aboriginal students in post-secondary education. Alberta Counselor, 29(1), 28-33.

Hare, J. (2011). Indigenous knowledge in education. In O. Dickason \& D. Long (Eds.), Visions of the Heart ( $3^{\text {rd }}$ ed.) (pp. 90-112). Don Mills: Oxford University Press. 
Kanu, Y. (2011). Integrating Aboriginal perspectives into the school curriculum. Toronto: University of Toronto Press.

Kirkness, V. J., \& Barnhardt, R. (1991). First Nations and higher education: The four R'srespect, relevance, reciprocity, responsibility. In R. Hayoe \& J. Pan (Eds.), Knowledge across cultures: A contribution to dialogue among civilizations. Hong Kong: Comparative Education Research Centre, The University of Hong Kong. Retrieved from http://www/ankn.uaf.edu/IEW/winhec/FourRs2ndEd.html

Kitchen, J., Cherubini, L., Trudeau, L., \& Hodson, J. (2010). Weeding out or developing capacity? Challenges for Aboriginal teacher education. Alberta Journal of Educational Research, 56(2), 107-123.

Kovach, M. (2009). Indigenous methodologies: Characteristics, conversations, and contexts. Toronto, ON: University of Toronto Press.

Kulig, J., Lamb, M., Solowoniuk, J., Weaselfat, R., Shade, C., Healy, L., White, T., \& Crowshoe-Hirsch, H. (2010). Nurturing a dream: The support program for Aboriginal nursing students. First Nations Perspectives: The Journal of the Manitoba First Nations Resource Centre, 3(1), 89-109.

Landon, R. (2012). We can do it (education) better: An examination of four secondary school approaches for Aboriginal students in northwestern Ontario (Doctoral dissertation, University of Toronto). Retrieved from TSpace http://hdl.handle.net/1807/34776

Larimore, J. A., \& McClellan, G. S. (2005). Native American student retention in U.S. postsecondary education. New Directions for Student Services, 2005(109), 17-32. https://doi.org/10.1002/ss.150

Lowan-Trudeau, G. (2012). Methodological métissage: an interpretive Indigenous approach to environmental education research. Canadian Journal of Environmental Education 17, 113-130.

McMullen, B., \& Rohrbach, A. (2003). Distance education in remote Aboriginal communities: Barriers, learning styles and best practices. Prince George, BC: College of Caledonia Press.

Means, B., Toyama,Y., Murphy. R., Bakia, M., \& Jones, K. (2009). Evaluation of evidencebased practices in online learning: A meta-analysis and review of online-learning studies. Washington, D.C.: U.S. Department of Education.

Munro, Y. (2012, June). Performing marginalization: Unpacking online testimonials of racialized/poor youth from Canada and American post-secondary access initiatives. A paper presented at the 32nd Annual Conference of The Society for Teaching and Learning in Higher Education. Montreal, Canada.

Munroe, E., Borden, L., Orr, A., \& Meader, J. (2014). Decolonizing Aboriginal education in the 21 st Century. McGill Journal of Education, 48(2), 317-336. https://doi.org/10.7202/1020974ar

OECD (2017). Supporting educational achievement among Indigenous students In Promising Practices in Supporting Success for Indigenous Students. OECD Publishing, Paris. http://dx.doi.org/10.1787/9789264279421-en

Parkin, A. (2015, June). International report card on public education. Toronto: Environics Institute. Retrieved from: http://environicsinstitute.org/uploads/instituteprojects/environics $\% 20$ institute $\% 20-\% 20$ parkin $\% 20-\%$ 0international\%20report\%200n\%20education\%20-\%20final\%20report.pdf

Pidgeon, M. (2009). Pushing against the margins: Indigenous theorizing of "success" and retention in higher education. Journal of College Student Retention, 10(3), 339-360. https://doi.org/10.2190/cs.10.3.e

Reyhner, J., \& Dodd, J. (1995, January). Factors affecting the retention of American Indian and Alaska Native students in higher education. A paper presented at the $1^{\text {st }}$ Annual Expanding Minority Opportunities National Conference, Arizona State University, Tempe, AZ.

Saldana, J. (2013). The coding manual for qualitative researchers (2nd ed.). London: Sage. 
Slee, J. (2010). A systemic approach to culturally responsive assessment practices and evaluation. Higher Education Quarterly, 64(3), 246-260. https://doi.org/10.1111/j.1468-2273.2010.00464.x

Smith, C., \& Gottheil, S. (2011). Increasing accessibility: Lessons learned in retaining special population students in Canada. College \& University, 86(4), 47-52.

Swail, W., Redd, K., \& Perna, L. (2003). Retaining minority students in higher education: A framework for success. Higher Education Reports, 30(20), 1-172.

Tinto, V. (1975). Dropout from higher education: A theoretical synthesis of recent research. Review of Educational Research, 45(1), 89-125. https://doi.org/10.2307/1170024

Tinto, V. (2012). Completing college: Rethinking institutional action. Chicago: University of Chicago Press. https:/ / doi.org/10.7208/chicago/9780226804545.001.0001

Toulouse, P. (2007). Supporting Aboriginal student success: Self-esteem and identity, a living teachings approach. Retrieved from http://www.edu.gov.on.ca

Toulouse, P. (2011). Achieving Aboriginal student success: A guide for $K$ to 8 classrooms. Winnipeg: Portage and Main Press.

Truth and Reconciliation Commission of Canada (TRCC). (2015). Honouring the truth, Reconciling for the future: Summary of the final report of the truth and reconciliation committee. Ottawa: Truth and Reconciliation Commission.

Valentine, J. C., Hirschy, A. S., Bremer, C. D., Novillo, W., Castellano, M., \& Banister, A. (2011). Keeping at-risk students in school: A systematic review of college retention programs. Educational Evaluation and Policy Analysis, 33(2), 214-234. https://doi.org/10.3102/0162373711398126

Walberg, B. (2008). Responding to the needs of post-secondary Aboriginal education: The development of the Indigenous leadership and community development program. In K. Knopf (Ed.), Aboriginal Canada (pp. 100-119). Ottawa: University of Ottawa Press.

Whitely, J. (2014). Supporting educational success for Aboriginal students: Identifying key influences. McGill Journal of Education 49(1), 155-181. https://doi.org/10.7202/1025776ar

Williams, M. S. (2004, December). Access to public universities: Addressing systemic inequalities. A paper presented at the Conference on Taking Public Universities Seriously. University of Toronto, Toronto, Canada.

Wilson, S. (2008). Research is Ceremony: Indigenous research methods. Halifax: Fernwood.

Woltering, V., Herrier, A., Spitzer, K., \& Spreckelson, C. (2009). Blended learning positively affects students' satisfaction and the role of the tutor in the problembased learning process: Results of a mixed-method evaluation. Advances in Health Science Education Theory and Practice, 14(5), 725-38. https://doi.org/10.1007/s10459-009-9154-6

Zinga, D., \& Gordon, M. (2014). 'Racism under the radar': Student perceptions of school experiences in a multicultural context. Race Ethnicity and Education 19(5), 10881116. https://doi.org/10.1080/13613324.2014.885429 